\title{
SCIDOC
}

\author{
International Journal of Dentistry and Oral Science (IJDOS) \\ ISSN: 2377-8075
}

\section{Evaluation of Coincidence between Facial and Dental Midlines in Relation to Esthetics - A Retrospective Study}

Research Article

Nadhirah Faiz ${ }^{1}$, Jessy $\mathrm{P}^{2 *}$, Iffat Nasim ${ }^{3}$, Subhabrata Maiti ${ }^{4}$

${ }^{1}$ Saveetha Dental College and Hospitals, Saveetha Institute of Medical and Technical Sciences, Saveetha University, Chennai, India.

${ }^{2}$ Senior Lecturer, Department of Pedodontics and Pediatric Dentistry, Saveetha Dental College and Hospitals, Saveetha Institute of Medical and Technical Sciences, Saveetha University, Chennai, 600077, India.

${ }^{3}$ Professor, Head of Department, Department of Conservative Dentistry and Endodontics, Saveetha Dental College and Hospitals, Saveetha Institute of Medical and Technical Sciences, Saveetha University, Chennai, 600077, India.

${ }^{4}$ Senior Lecturer, Department of Prosthodontics, Saveetha Dental College and Hospitals, Saveetha Institute of Medical and Technical Sciences, Saveetha University, Chennai, 600077, India.

\section{Abstract}

The current world that we live in is a world filled with comparison and high expectations. Previously, when a patient visited a dentist, the complaint would be in relation to lack of function. Nowadays, people with a set of good teeth walk into the clinic with the desire of making it more esthetic. Dental esthetics is a field of dentistry concerned especially with the appearance of dentition as achieved through its arrangement, form and color. From functional demands, the patients of the current world, have shifted their demands to esthetics. Esthetics can be simply detected based on the correlation of facial and dental midlines. The aim of the study was to determine the evaluation of coincidence between facial and dental midlines in relation to esthetics. This retrospective study was done by reviewing the patient case records. After reviewing 86,000 patient case sheet records, a sample size of 900 patients were selected. The photographs of those patients were retrieved from Dental Information Archiving Software. The photographic analysis was done by using photoshop software (Adobe). The obtained data was entered in Excel spreadsheet and imported to SPSS software version 20.0. Chi square test was performed. The level of significance was set at $\mathrm{p}<0.05$. The results proved that $44.7 \%$ show no coincidence of facial and dental midlines, $38.5 \%$ had left side discrepancies and $61.5 \%$ had right side discrepancies. Above 30 years of age was found to have less coincidence with the female predominance,There was statistical significant difference between coincidence of facial and dental midline based on age groups.Within the limits of the study, it can be concluded that $44.7 \%$ show no coincidence of facial and dental midlines, In cases where the midline doesn't coincide, the right side discrepancies were seen to be more common.

Keywords: Dental Midline; Esthetics; Facial Midlines; Coincidence.

\section{Introduction}

An imperfect positioning of teeth in the jaws can be termed as a malocclusion. A malocclusion can be classified into minor and severe malocclusions by nature. For minor malocclusions, restorative, prosthetic or orthodontic treatment without surgery would be more than sufficient. In cases of severe malocclusions, surgical treatment would yield optimum results. In many of the cases, just using orthodontic treatment can not yield the result the patient desires. In such times, orthodontic treatment along with surgical treatment is advised $[1,2]$. At one point of time, esthetic dentistry was a speciality only for an orthodontist. But in current times, an oral maxillofacial surgeon, periodontist [3] and prosthodontist can be considered estheticians [4] . Every dentist is responsible for the final outcome of the restoration and hence is considered an integral factor in maximizing esthetics [5-7].

Dental esthetics is a field of dentistry concerned especially with the appearance of dentition as achieved through its arrangement, form and color. This does not just cover the complete dentition and also aims at increasing the overall facial attractiveness of the patient $[8,9]$. The importance of dentofacial appeal in regard to

*Corresponding Author:

Jessy P,

Senior Lecturer, Department of Pedodontics and Pediatric Dentistry, Saveetha Dental College and Hospitals, Saveetha Institute of Medical and Technical Sciences, Saveetha University, Chennai, 600077, India.

Tel: 8861646189

E-mail: jessyp.sdc@saveetha.com

Received: November 10, 2020

Accepted: December 15, 2020

Published: December 18, 2020

Citation: Nadhirah Faiz, Jessy P, Iffat Nasim, Subhabrata Maiti. Evaluation of Coincidence between Facial and Dental Midlines in Relation to Esthetics - A Retrospective Study Int J Dentistry Oral Sci. 2020;7(12):1216-1221. doi: http://dx.doi.org/10.19070/2377-8075-20000240

Copyright: Jessy $\mathbf{P}^{\circ} 2020$. This is an open-access article distributed under the terms of the Creative Commons Attribution License, which permits unrestricted use, distribution and reproduction in any medium, provided the original author and source are credited. 
the individual's psycho-social well-being is a proven fact. One of the most important factors that affect people's smiles is teeth. A dental restoration's positive impact on the patient's smile, appearance, self-confidence and overall mental health can not be underestimated [10]. Dental aesthetic corrections can be categorized into facial esthetics, esthetic orthodontics and esthetic prosthodontics. The type of malocclusion, the degree of malocclusion, age, patients' esthetic desires, practitioners' style of treatment as well as gender predilection can influence the final esthetic treatment the patient will be subjected to.

In the past world, functional demands were the main and sole focus of dental treatments [3,11-13]. With time and technological advancements in dentistry, the main focus of demands had shifted to giving the patient the maximum esthetic values $[14,15]$. Esthetics can be enhanced in cases where the patient maintains good oral hygiene [16], has replacement of missing teeth with a well designed prosthesis [17-19] and in cases where the practitioner advised in treatment using ceramic restorations [18-20].

Dental esthetics can be said to be a subjective field as the perception of esthetics vary based on a variety of factors and beliefs. Acceptance of dental aesthetics varies from person to person based on the age of the patient [21], gender of the patient, recognition of tooth color of the patient [22-28], retained primary teeth [29-31] as well as correlation of facial and dental midlines [22-27]. Symmetry can be considered as an essential requirement to bring harmony and balance in facial esthetics [32]. In order to understand the concept behind esthetics, it is imperative to have sufficient knowledge of midlines. A vertical line bisecting a horizontal line originating at the exocanthion of one eye and reaching the other eye's exocanthion can be defined to be the facial midline [33]. It can be referred to as the primary reference line to maximize facial esthetics [34]. A recent study was conducted to standardize the facial midline landmarks and it has been found that oral commissures, natural dental midline and tip of the philtrum in this order is the preferred landmark to determine the facial midline $[22,23,35-37]$. The incisive papilla is commonly located between the maxillary central incisors exactly and is considered as one of the predictable intraoral landmarks to determine dental and facial midline coincidence [32, 38].

Achieving coincidental facial and dental midlines is a well established objective in orthodontic treatment. Coinciding dental and facial midlines are a useful guide to achieving good occlusal interdigitation. A symmetric dental arrangement of teeth is thought to be an important factor of an attractive smile [39] and asymmetry can impair the dental aesthetics. Patients can easily recognise an asymmetry in midlines. In clinical practice, orthodontists and prosthodontists often encounter malocclusions where discrepancies exist between facial and dental midlines [40]. As the discrepancies increase, the complexity and duration of the orthodontic treatment also increases. The decision of whether to extract teeth for the midline correction is slightly difficult as the discrepancy between facial and dental midlines is very small.

With every research published till date, multiple parameters have been added to increase the esthetic values of a smile. One such recent parameter added is facial and dental midline coincidence. Understanding the prevalence of coincidence between dental and facial midlines, it will give better understanding of the phenomenon and enhanced treatment planning can be utilised in its correc- tion at younger ages. The overall aim of the study was to evaluate the coincidence between facial and dental midlines.

\section{Materials And Methodology}

\section{Study Design}

Inclusion and exclusion criteria for the given study are given as follows -

Inclusion criteria:

1. Patients of 18 years to 40 years were included in the study 2. Patients have to have no missing teeth in order to be considered as a part of the study.

\section{Exclusion criteria:}

1. Patients who had missing teeth

2. Patients with skeletal deformities were excluded

3. Patients with ages below the age of 18 years were excluded from the sample size.

\section{Study Setting}

The study was conducted in a universal setting in a South Indian population. The positives of the study conducted was the similar ethnicity of the sample size of the study as well as the online availability of the photographs of the patients. This study was approved by the Ethical Institutional Review Board and was allocated the ethical approval number SDC/SIHEC/2020/DIASDATA/0619-0320. There were 2 reviewers involved in the data collection process. Both reviewers of the study were responsible for the data collection upon reviewing intraoral photos of the patients selected for the study. The cases were selected on the basis of inclusion and exclusion criteria.

\section{Sampling}

A retrospective study was conducted in an institutional setup of the patients visiting over the duration from June 2019 till March 2020 . This retrospective was done by reviewing the patient case sheet records. After reviewing 86,000 patient case sheet records, a sample size of 900 patients were selected.

\section{Study design and Data collection}

The internal validity of the study is applicable. The external validity of the study defines the eligible criteria of the sample size population. The photographs of the patients were collected from the Dental Information Archiving Software with the age group between 18years to 40 years. The case sheets of the given sample size of the study are reviewed by the usage of intraoral photos of the patients. Cross verification of the patient's data done by two reviewers to prevent errors. The measure to prevent errors done is to review the observer which will minimize the sampling bias. The photographs were imported to photoshop software (Adobe) where the two lines, facial midline (straight line drawn based on nasion,tip of the nose and philtrum tip) and dental midline ( line drawn through the contact area of two central incisors) were marked in two different color codes (red and yellow color mark- 
ing respectively) and the coincidence was checked and the discrepancies towards right or left were recorded keeping the facial midline as a standard.

\section{Data Analytics}

The obtained data was tabulated using the Microsoft Excel Spreadsheet and analysis of the data was performed using statistical software IBM SPSS version 20.0 where chi square analytical tests were done.

\section{Results \& Discussion}

The study conducted was aimed to determine the evaluation of facial and dental midline coincidence. A sample size of $900 \mathrm{pa}-$ tients was narrowed down from a patient flow of 86,000 , and those 900 patient case sheets were reviewed of which $37.4 \%$ are females and $62.6 \%$ are males. Facial and dental midlines coincidence was seen in $55.3 \%$ of the cases whereas $44.7 \%$ show no coincidence of facial and dental midlines(Figure 2), 38.5\% have left side discrepancies and $61.5 \%$ have right side discrepancies (Figure 3). In patients with no coincidence of midlines , $60.2 \%$ of the patients are below 30 years of age and $39.8 \%$ of the patients are above 30 years. Amongst the patients with coincident midlines, $67.3 \%$ are below 30 years of age and $32.7 \%$ are above 30 years of age (figure 4). There was significant association between facial and dental midline coincidence based on age, Pearsons' chi square value $=4.832, \mathrm{P}$ value $=0.028,(\mathrm{P}<0.05)$ which is statistically significant. In patients with no coincidence midlines, 35.6\% of the patients are females and $64.4 \%$ of the patients are males. Amongst the patients with coincident midlines, $38.8 \%$ are females and $61.2 \%$ are males (figure 5). There was no significant association between facial and dental midline coincidence based on gender, Pearsons' chi square value $=0.963$, $\mathrm{p}$ value $=0.326,(\mathrm{P}>0.05)$ which is statistically not significant. Discussing the discrepancies related to midline,the left side discrepancies of the midline, both the age groups found to have right side discrepancy, $65.2 \%$ are below 30 years and $34.8 \%$ are above 30 years. In patients with coincident midlines, $67.3 \%$ are below 30 years and $32.7 \%$ are above 30 years. In patients with right side discrepancies of the midline, $57.1 \%$ are below 30 years and $42.9 \%$ are above 30 years (figure 6). There was significant association between discrepancies of the midlines based on age, Pearsons' chi square value $=7.532$, $\mathrm{p}$ value $=0.023,(\mathrm{P}<0.05)$ which is statistically significant. Based on Gender both males and females had a more discrepancy towards right side compared to the left side. In patients with left side discrepan-

Figure 1. This figure represents the technique utilised to obtain the midline coincidence presence or absence. Red line denotes the facial midline and yellow line denotes dental midline. In this picture, the facial and dental midlines were found to have left side midline discrepancy, that is, the dental midline has shifted towards the left side.

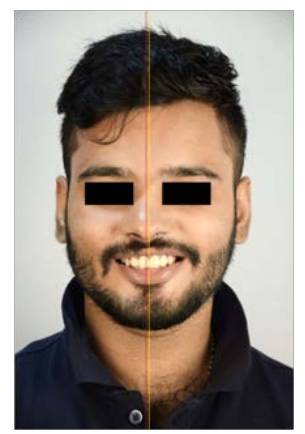

Figure 2. Representing Coincidence between facial and dental midlines.Coincidence was not present $44.7 \%$. Coincidence between facial and midline found was $55.3 \%$.

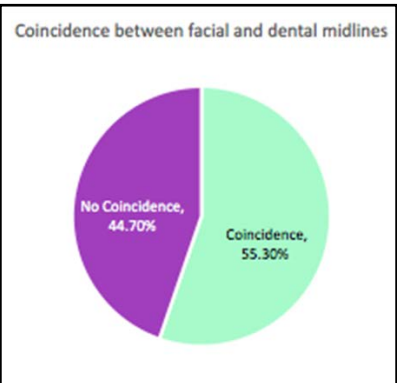

Figure 3. Representing discrepancies between facial and dental midlines.Right side discrepancies was found to be $61.50 \%$ when compared to left side.

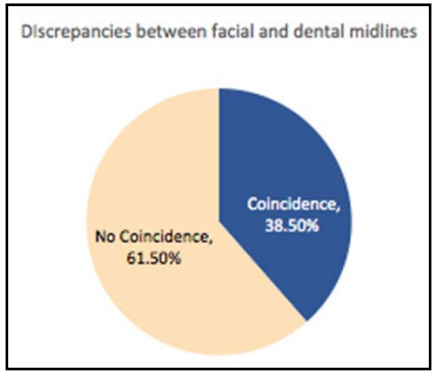


Figure 4. The above graph represents association between Coincidence of Midline and Age groups. $\mathrm{X}$ axis denotes the age groups of patients (purple - absence of midline coincidence, light green - presence of midline coincidence) and $\mathrm{Y}$ axis denotes the number of patients in the study population.It was found that less coincidence of midlines in patients with above 30 years of age $(67.3 \%)$, There was statistical significant difference, Pearsons' chi square value $=4.832 ; P$ value $=0.028$;

$(\mathrm{p}<0.05)$.

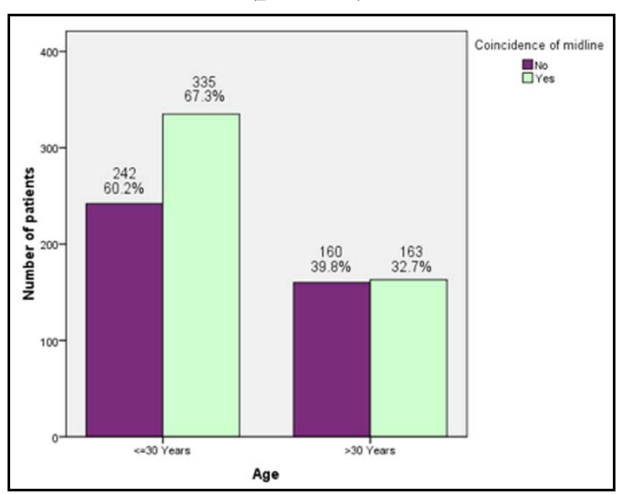

Figure 5. Bar graph representing association between Coincidence of Midline and Gender groups. $\mathrm{X}$ axis denotes the Gender of the patient (purple - absence of midline coincidence, light green - presence of midline coincidence) and $\mathrm{Y}$ axis denotes the number of patients of study population. It was found that the coincidence of midline was less among females compared to males, however there is no statistical significant difference, $($ Pearsons' chi square value $=0.963 ; \mathrm{p}$ value $=0.326$; $P>0.05)$.

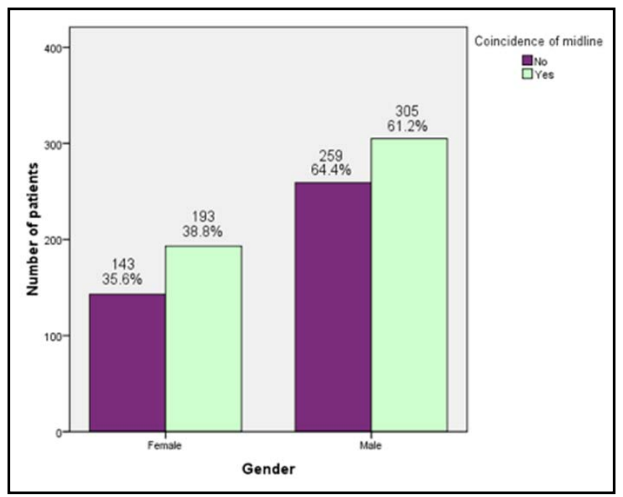

Figure 6. Bar graph representing association between Discrepancies of Midline Coincidence and age groups. $\mathrm{X}$ axis denotes the age of the patients (blue-left midline discrepancies, green-midline coincidence, beige-right midline discrepancies) and $\mathrm{Y}$ axis denotes the number of patients of the study population. In both age groups discrepancy towards the right side was found to be common. Chi square test showed, Pearsons' chi square value $=7.532 ; \mathrm{p}$ value $=0.023 ;(\mathrm{P}<0.05)$ It was found that the difference was of statistical significance.

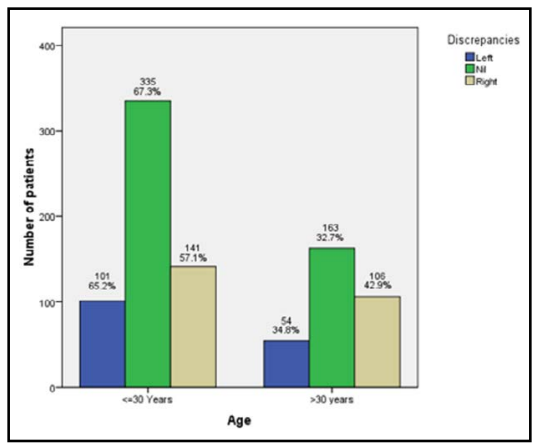

cies of the midline, $37.4 \%$ are females and $62.6 \%$ are males. In patients with coincident midlines, $38.8 \%$ are females and $61.2 \%$ are males. In patients with right side discrepancies of the midline, $34.4 \%$ are females and $65.6 \%$ are males (figure 7 ). There was no significant association between discrepancies of the midlines based on gender, Pearsons' chi square value $=1.331, \mathrm{p}$ value $=$ 0.514, $(\mathrm{P}>0.05)$ which is not statistically significant.

In this study, it can be seen that the association between midline coincidence and gender as well as the association of midline coin- cidence with age groups are of significant value, however Below 30 years of age was found to have maximum coincidence with the male predominance. There is a lot of literature present to support as well as to oppose this conducted study. The literature given by Jain AR et al., 1999, supports the study conducted by stating that the coincidence of facial and dental midline is seen in $86 \%$ of the sample size. The other supporting study was given by Priyadharshini et al., 2019. This study states that the majority of the female population have the coincidence of facial and dental midlines which is $69 \%$ of the sample size taken. Relevant 
Figure 7. Bar graph representing association between Discrepancies of Midline Coincidence based on gender. $\mathrm{X}$ axis denotes the gender of the patients (blue-left midline discrepancies, green-midline coincidence, beige-right midline discrepancies) and $\mathrm{Y}$ axis denotes the number of patients in the study population.In both males and females discrepancies towards right was more than left discrepancy. (Pearsons' chi square value $=1.331 ; \mathrm{p}$ value $=0.514 ; \mathrm{P}>0.05$ ). It was found that the difference was not of statistical significance.

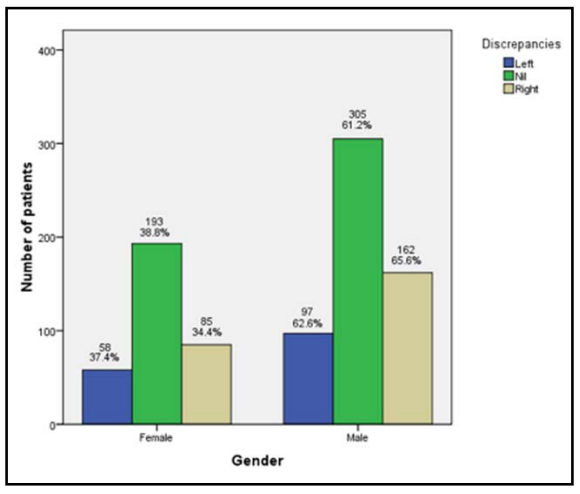

opposing literature to the conducted study is present too. One of which is Johnston CD et al., 1999 [22], it says that $2 \mathrm{~mm}$ or more discrepancies are likely to be noticed in $83 \%$ of the sample size by orthodontists. Another study was given by Khan M et al., [20, 19, 24], which stated that the maxilla- mandible midline coincidence is $64.1 \%$ but facial and dental midlines only coincide in $47 \%$ of the sample size. Previous literature are mainly based on the extent of the acceptable range of discrepancy between dental midline and facial midline that is approximately $2-3 \mathrm{~mm}$ deviation, and there was no definite reference of the midline [22, 23, 37]. In the two studies, $70 \%$ of the dental midline compatibility with facial midline has been reported [41]. The major issue of the studies in this area is the shortage of scientific literature providing the relationship between anatomical landmarks of the mouth and facial midlines. In this study conducted, there lies one limitation of the study, which is, observer bias. To undo the limitation could be an outside who is unaware of the topic and what results are expected.

The current world that we live in is a world filled with comparison and high expectations. Previously, when a patient visited a dentist, the complaint would be in relation to lack of function. Nowadays, people with a set of good teeth walk into the clinic with the desire of taking their good teeth and making that into the best version. Many reasons can be associated with this esthetic treatment desire. People who lack confidence feel like they are capable of a lot more after such treatments and this results in a boost of confidence in their physical, mental, professional and social aspects. They tend to stand taller, with a sparkle in their eyes showing off a little higher self esteem levels.

In this day and age along with high expectations of patients, it is very important to educate clinical practitioners and future dentists of the parameters to ensure smiles restored as of highest esthetic values. As practitioners of the current world, it is extremely important that we not only restore functional demands of a patient but also meet their esthetic desires and do so while providing them treatments with the latest and best technological advancements available in the shortest duration possible. The aim of this study was to increase the knowledge and awareness of the practitioners on the topic of midline coincidence. This incremental increase in knowledge of the dentist will help in enabling them understand the importance of midline correlations and provide them access to adequate knowledge and awareness in early detection and advanced computerized analysis which can thus yield alternative treatments of significantly lesser procedure duration to provide increased esthetics and maximum satisfaction of the patients' desires.

\section{Conclusion}

Within the limits of the study, it can be concluded that $44.7 \%$ show no coincidence of facial and dental midlines, In cases where the midline doesn't coincide, the right side discrepancies were seen to be more common. There was strong association between midline coincidence and discrepancies of midline based on age groups however no association was found on gender.

\section{Author Contributions}

First author, Dr Nadhirah Faiz, performed the analysis, and interception and wrote the manuscript. Second author, Dr. Jessy, contributed to conception, data design, analysis interpretation and critically revised manuscript. The third author, Dr Iffat Nasim , Participated in the study and revised the manuscript . The fourth author, Dr.Subhabrata Maiti, participated in data design and revised the manuscript as per guideline, alignments and formatting. All the authors have discussed the results and contributed to the final manuscript.

\section{Acknowledgement}

Thanks to Saveetha Dental College for allowing me to review the case sheets.

\section{References}

[1]. Ganapathy D, Sathyamoorthy A, Ranganathan H, Murthykumar K. Effect of Resin Bonded Luting Agents Influencing Marginal Discrepancy in All Ceramic Complete Veneer Crowns. J Clin Diagn Res. 2016 Dec;10(12):ZC67ZC70.Pubmed PMID: 28209008.

[2]. Ajay R, Suma K, Ali SA, Kumar Sivakumar JS, Rakshagan V, Devaki V, et al. Effect of Surface Modifications on the Retention of Cement-retained Implant Crowns under Fatigue Loads: An In vitro Study. J Pharm Bioallied Sci. 2017 Nov;9(Suppl 1):S154-S160.Pubmed PMID: 29284956.

[3]. Jyothi S, Robin PK, Ganapathy D. Periodontal health status of three different groups wearing temporary partial denture. Res J Pharm Technol. 
2017;10(12):4339-42.

[4]. Turvey TA. Orthognathic surgery: a significant contribution to facial and dental esthetics. J Am Dent Assoc. 1988 Sep;117(4):49E-55E.Pubmed PMID: 3183254.

[5]. Duraisamy R, Krishnan CS, Ramasubramanian H, Sampathkumar J, Mariappan S, Navarasampatti Sivaprakasam A. Compatibility of Nonoriginal Abutments With Implants: Evaluation of Microgap at the Implant-Abutment Interface, With Original and Nonoriginal Abutments. Implant Dent. 2019 Jun;28(3):289-295.Pubmed PMID: 31124826.

[6]. Kannan A. Effect of Coated Surfaces influencing Screw Loosening in Implants: A Systematic Review and Meta-analysis. World J. Dent. 2017 Nov;8(6):496-502.

[7]. Ashok V, Nallaswamy D, Benazir Begum S, Nesappan T. Lip Bumper Prosthesis for an Acromegaly Patient: A Clinical Report. J Indian Prosthodont Soc. 2014 Dec; 14(Suppl 1):279-82.Pubmed PMID: 26199531.

[8]. Phillips C, Tulloch C, Dann C. Rating of facial attractiveness. Community Dent Oral Epidemiol . 1992 Aug;20(4):214-20.

[9]. Shaw WC, Rees G, Dawe M, Charles CR. The influence of dentofacial appearance on the social attractiveness of young adults. Am J Orthod. 1985 Jan;87(1):21-6.Pubmed PMID: 3855347.

[10]. Proffit WR, Fields Jr HW, Sarver DM. Contemporary orthodontics. Elsevier Health Sciences; 2006 Dec 8:768.

[11]. Vijayalakshmi B, Ganapathy D. Medical management of cellulitis. Res J Pharm Technol. 2016;9(11):2067-70.

[12]. Selvan SR, Ganapathy D. Efficacy of fifth generation cephalosporins against methicillin-resistant Staphylococcus aureus-A review. Res J Pharm Technol. 2016;9(10):1815-8.

[13]. Subasree S, Murthykumar K. Effect of Aloe Vera in Oral Health-A Review. Res J Pharm Technol. 2016;9(5):609-12.

[14]. Samorodnitzky-Naveh GR, Geiger SB, Levin L. Patients' satisfaction with dental esthetics. J Am Dent Assoc. 2007 Jun 1;138(6):805-8.

[15]. Akarslan ZZ, Sadik B, Erten H, Karabulut E. Dental esthetic satisfaction, received and desired dental treatments for improvement of esthetics. Indian J Dent Res. 2009 Apr-Jun;20(2):195-200.Pubmed PMID: 19553722.

[16]. Basha FYS, Ganapathy D, Venugopalan S. Oral Hygiene Status among Pregnant Women [Internet].Research Journal of Pharmacy and Technology. 2018;11: 099

[17]. Venugopalan S, Ariga P, Aggarwal P, Viswanath A. Case Report: Magnetically retained silicone facial prosthesis. Niger. J. Clin. Pract. 2014 Mar 27:17(2):260-4.

[18]. Kannan A, Venugopalan S. A systematic review on the effect of use of impregnated retraction cords on gingiva. Res J Pharm Technol. 2018;11(5):2121-6.

[19]. Ranganathan H, Ganapathy DM, Jain AR. Cervical and Incisal Marginal Discrepancy in Ceramic Laminate Veneering Materials: A SEM Analysis. Contemp Clin Dent. 2017 Apr-Jun;8(2):272-278.Pubmed PMID: 28839415

[20]. Ashok V, Suvitha S. Awareness of all ceramic restoration in rural population. Res J Pharm Technol. 2016;9(10):1691-3.

[21]. Vallittu PK, Vallittu AS, Lassila VP. Dental aesthetics-a survey of attitudes in different groups of patients. J Dent. 1996 Sep 1;24(5):335-8.

[22]. Johnston CD, Burden DJ, Stevenson MR. The influence of dental to facial midline discrepancies on dental attractiveness ratings. Eur J Orthod. 1999 Oct;21(5):517-22.
[23]. Beyer JW, Lindauer SJ. Evaluation of dental midline position. Semin Orthod. 1998 Sep 1;4(3):146-152.

[24]. Khan M, Kazmi SMR. Coincidence of Dental Midline with Facial Midline in a Sample of Pakistani Population. J Coll Physicians Surg Pak. 2019 Mar;29(3):210-213.Pubmed PMID: 30823943.

[25]. Jayalakshmi NS, Ravindra S, Nagaraj KR, Rupesh PL, Harshavardhan MP. Acceptable Deviation between Facial and Dental Midlines in Dentate Population. J Indian Prosthodont Soc. 2013 Dec;13(4):473-7. PMID: 24431778.

[26]. Brisman AS. Esthetics: a comparison of dentists' and patients' concepts. J Am Dent Assoc. 1980 Mar;100(3):345-52.Pubmed PMID: 6928165.

[27]. Tjan AH, Miller GD, The JG. Some esthetic factors in a smile. J Prosthet Dent. 1984 Jan;51(1):24-8.Pubmed PMID: 6583388.

[28]. Jain AR, Dhanraj M. A clinical review of spacer design for conventional complete denture. Biol. Med. 2016;8(5):1.

[29]. Robinson S, Chan MF. New teeth from old: treatment options for retained primary teeth. Br Dent J. 2009 Oct 10;207(7):315-20.Pubmed PMID: 19816477.

[30]. Bjerklin K, Bennett J. The long-term survival of lower second primary molars in subjects with agenesis of the premolars. Eur J Orthod. 2000 Jun;22(3):245-55.Pubmed PMID: 10920557.

[31]. Ith-Hansen K, Kjaer I. Persistence of deciduous molars in subjects with agenesis of the second premolars. Eur J Orthod. 2000 Jun;22(3):239-43. Pubmed PMID: 10920556.

[32]. Bidra AS, Uribe F, Taylor TD, Agar JR, Rungruanganunt P, Neace WP. The relationship of facial anatomic landmarks with midlines of the face and mouth. J Prosthet Dent. 2009 Aug;102(2):94-103.Pubmed PMID: 19643223.

[33]. Academy of Prosthodontics. The Glossary of Prosthodontic Terms. Mosby Journal Reprint Department; 1994.70 p.

[34]. Lombardi RE. The principles of visual perception and their clinical application to denture esthetics. J Prosthet Dent. 1973 Apr;29(4):358-82.Pubmed PMID: 4570911.

[35]. Cardash HS, Ormanier Z, Laufer BZ. Observable deviation of the facial and anterior tooth midlines. J Prosthet Dent. 2003 Mar;89(3):282-5.Pubmed PMID: 12644804.

[36]. Rosenstiel SF, Ward DH, Rashid RG. Dentists' preferences of anterior tooth proportion--a web-based study. J Prosthodont. 2000 Sep;9(3):123-36.Pubmed PMID: 11179463.

[37]. Kokich VO Jr, Kiyak HA, Shapiro PA. Comparing the perception of dentists and lay people to altered dental esthetics. J Esthet Dent. 1999;11(6):311-24. Pubmed PMID: 10825866.

[38]. Zarb GA, Bolender CL, Carlsson GE, Boucher CO. Boucher's Prosthodontic Treatment for Edentulous Patients. Mosby Incorporated; 1997. 558 p.

[39]. Jain AR, Nallaswamy D, Ariga P, Ganapathy DM. Determination of correlation of width of maxillary anterior teeth using extraoral and intraoral factors in Indian population: A systematic review. World J Dent. 2018 Jan;9:68-75.

[40]. Jerrold L, Lowenstein LJ. The midline: diagnosis and treatment. Am J Orthod Dentofacial Orthop. 1990 Jun 1;97(6):453-62.

[41]. Miller EL, Bodden WR Jr, Jamison HC. A study of the relationship of the dental midline to the facial median line. J Prosthet Dent. 1979 Jun;41(6):657-60.Pubmed PMID: 374721. 